\title{
Effects of Stereoscopic 3D Contents on the Process of Learning to Build a Handmade PC
}

\author{
Aika Mukai \\ Fujitsu Hokuriku Systems Limited \\ 3-4-30, Masuizumi, Kanazawa-City, Ishikawa, Japan \\ E-mail: nkmtq921@ venus.kanazawa-it.ac.jp

\section{Yoshio Yamagishi*} \\ Department of Media Informatics \\ Kanazawa Institute of Technology \\ 3-2, Yatsukaho, Hakusan-City, Ishikawa, Japan \\ E-mail: yamagisi@neptune.kanazawa-it.ac.jp
}

\section{Makoto J. Hirayama}

Department of Media Informatics

Kanazawa Institute of Technology

3-2 Yatsukaho, Hakusan-City, Ishikawa, Japan

E-mail: mako@infor.kanazawa-it.ac.jp

\section{Toshiya Tsuruoka}

Hokuriku Software Development Co., Ltd.

4-81-3, Yoneizumi-Town, Kanazawa-City, Ishikawa, Japan

E-mail: tsuruoka.toshiya@hsknet.com

\section{Tosh Yamamoto}

Division of Teaching and Learning

Kansai University

3-3-35, Yamate-Town, Suita-City, Osaka, Japan

E-mail: ctltosh@kansai-u.ac.jp

*Corresponding author

\begin{abstract}
We previously developed Web3D contents that simulate the procedure for assembling a handmade PC. The original motivation for this project was to enable media-informatics students to deepen their understanding of PC hardware. However, it was found that due to their lack of perspective, conveying information that relates to such virtual manufacturing was quite difficult using conventional 2D displays. In this study, we optimized the graphical contents for a stereoscopic environment that would allow proper perspective to be realized. No significant differences were identified between stereoscopic $3 \mathrm{D}$ cases and $2 \mathrm{D}$ cases. This result is considered to be due to
\end{abstract}


learner fatigue specific to stereoscopic 3D cases.

Keywords: Stereoscopy; 3D Modelling; PC Assembly; Interactive Simulation

Biographical notes: Aika Mukai is currently on the staff of Fujitsu Hokuriku Systems Limited, Japan. She earned her M.Eng. in System Design Engineering from Graduate School, Kanazawa Institute of Technology. Her master thesis is based on this work.

Yoshio Yamagishi is currently an Associate Professor in the Department of Media Informatics, Kanazawa Institute of Technology. In 1996, He received his D.S. degree in Theoretical Physics from Graduate School, Kanazawa University, Japan. Current his research interests include e-Learning System Design, Mobile Learning and 3D Computer Graphics.

Makoto J. Hirayama, Doctor in Engineering is a professor in the Department of Media Informatics, Kanazawa Institute of Technology. He researches into multimodal and multimedia communication technologies for e-Learning, entertainment and well-being systems.

Toshiya Tsuruoka is currently on the staff of Hokuriku Software Development Co., LTD., Japan. In 2008, He graduated from Department of Media Informatics, Kanazawa Institute of Technology. This work is partially based on his graduation thesis.

Tosh Yamamoto, Ph.D. is a professor in the Division of Teaching and Learning, Kansai University. He has been active in the area of e-Learning specialized in interactivity in e-Learning that brings learning effectiveness. He has been researching on how to design a robust e-Portfolio system in the higher education.

\section{Introduction}

Learning from experience is one of the traditional approaches for the education (Kolb, Rubin, \& McIntyre, 1974; Holman, Pavlica, \& Thorpe, 1997). Especially in science and engineering education, laboratory experiments, outdoor observations, physical activities, designing and constructing usually yield better comprehension to students than classroom lectures. In addition, repetitive practice is needed for developing some technical skills. However, due to the issues of resources, such experience-based learning environments are hardly acceptable for some educational organizations. Multimedia learning (Moreno \& Mayer, 1999; Mayer 2001) is the reasonable alternative. Multimedia interactive learning contents can provide virtual experiences in the situated learning. Hirayama (2010) showed that the role playing in augmented reality space is effective to language learning.

Recently produced stereoscopic 3D movies, such as "Avatar" (2009) and "Alice in Wonderland"(2010), have attracted considerable attention. These movies provided a new and fascinating experience to audiences wearing 3D glasses. A common observation was that people became addicted to Avatar to the extent that they experienced severe depression after watching the movie (Piazza, 2010). It is expected that stereoscopic 3D TV sets and PCs will become more common in the near future. Considering these facts, we are certain that stereoscopic 3D technology will play an important role in a future 
media, and will also affect the field of education. In fact, the application of stereoscopic 3D technology to education has already begun (Pang et al., 2006).

Stereoscopic 3D environments are expected to be superior to conventional 2D's in the representation of spatial objects such as molecular structures, architectural constructions and machineries. However, currently there are few actual examples of stereoscopic 3D contents for the academic classes. The difference between 2D and 3D in learning effects is still unclear. Similarly, the constructional method of the stereoscopic 3D learning environment is not common. In this paper we report the details of stereoscopic 3D learning contents that we developed, and then discuss the learning effects of the contents.

The beginning of our study is as follows. In the Department of Media-Informatics of Kanazawa Institute of Technology, students are required to build a handmade PC for a course titled "Major Lab/Exercise II.". This exercise considerably helps to deepen students' understanding of PC hardware. However, due to space and budgetary constraints, each group as opposed to each student is assigned one PC. Therefore, after each student has completed the PC assembly, he/she disassembles it for another student to repeat the same procedure. This must be repeated four or five times (depending on the number of persons in the group). As a result, it appeared to be a waste of time.

The presence of learning contents that can be used to simulate the virtual assembly of a handmade PC can provide an environment for students to experience PC assembly at any time regardless of their location. Yamagishi and Tsuruoka (2009) developed such contents by using Web3D. However, operation of the virtual assembly tool was found to be difficult using a conventional 2D display because of the lack of perspective. Therefore, in order to realize proper perspective, we plan to adapt our contents to fit stereoscopic 3D environments.

\section{Preliminary Work}

In this section, we briefly review our preliminary work. The usual procedure for assembling is as follows:

(1) Insert the memory module into the slot of the motherboard

(2) Insert the CPU into the socket of the motherboard

(3) Place the CPU cooler on the CPU

(4) Connect the power cable of the CPU cooler to the motherboard

(5) Set the HDD into the case

(6) Connect the SATA cable from HDD to the motherboard

(7) Set the optical drive into the case

(8) Connect a SATA cable from optical drive to the motherboard

(9) Set a power unit into the case

(10) Connect cables of the power line from the power unit to the motherboard, HDD and optical drive

Note that the insertion of the CPU, memory module, and cables requires correct positions and directions. Incorrect assembly will cause serious damage to the parts. 
In early 2008, Tsuruoka and Yamagishi began developing Web3D contents that are capable of simulating the assembly of general IBM PC compatibles. The first step to simulating the above procedure in a virtual $3 \mathrm{D}$ world involves the preparation of $3 \mathrm{D}$ models for all PC parts such as CPU and motherboard.

\subsection{Object Modeling}

Figures 1 and 2 show a part of the process of modeling the contents. The software LightWave 3D (Newtek Inc., 1994) was used to build almost all PC parts. During the modeling process, we attempted to minimize each object's polygons in order to reduce the file size of the contents, because these objects must be converted into the Web3D format and subsequently transferred over network. However, the quality of these models was retained in order to allow the object to be easily identified. This trade-off was one of the more challenging aspects of this project.

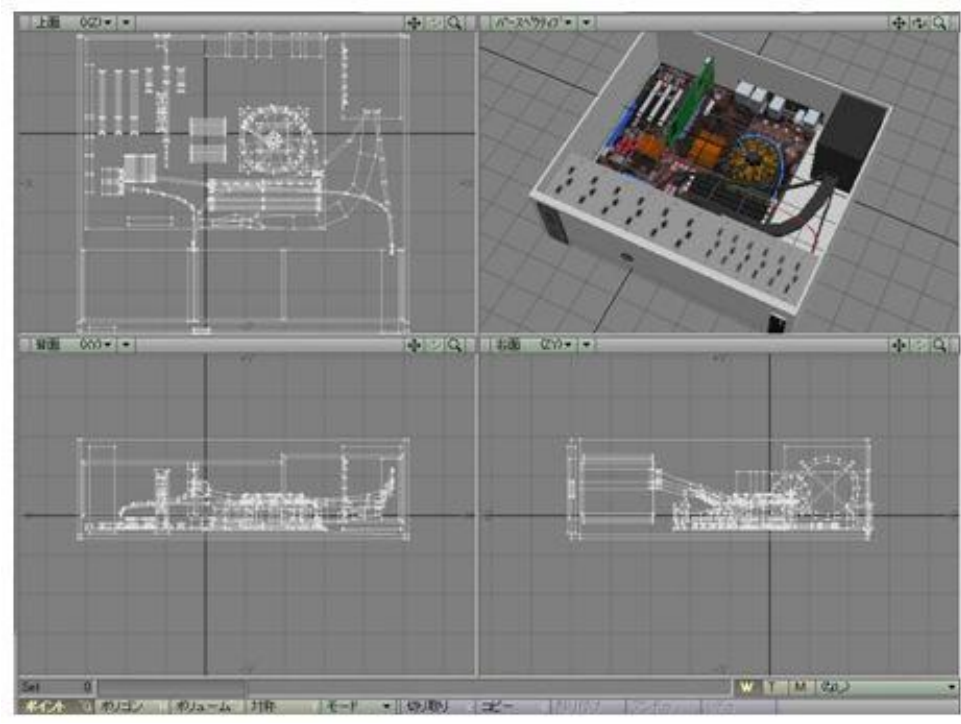

Figure 1. Modeling Process using LightWave 3D

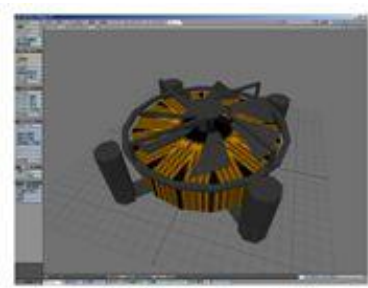

a) CPU Cooler

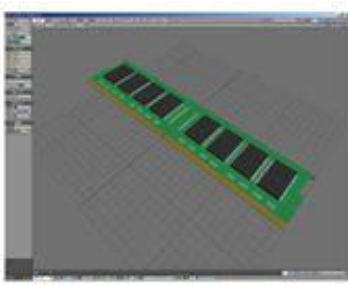

b) Memory Module

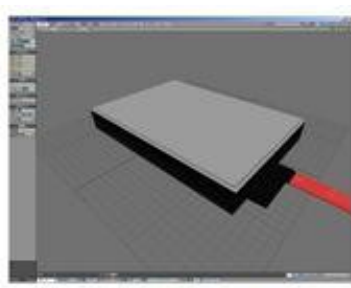

c) HDD (SATA)

Figure 2. Examples of Virtual PC Parts

\subsection{Web3D Conversion}

Web3D (Web3D Consortium, 1999) originated with Virtual Reality Modeling Language (VRML), which is an early trial aimed at realizing 3D virtual world on the web. The 
"Metaverse" such as SecondLife (Linden Lab, 2003) is partially based on the Web3D technologies. Quite a few trials to apply Metaverse or Web3D to the education have been done so far (for example, Mohler, 2000; Cerbo, Dodero, \& Papeleo, 2010; Lee \& Berge, 2011).

Currently, there are numerous Web3D formats such as X3D (Web3D Consortium, 1999), Viewpoint (Viewpoint Corporation, 2000), and Cult3D (Cycore System AB, 1997). Majority of them have resulted in improved quality and realism when compared with the old VRML. In this study, we chose the ShockWave 3D (Macromedia Inc., 2001) format, which was developed by Macromedia Inc. (a part of Adobe Systems Inc. since 2005). The major reason for choosing ShockWave 3D (SW3D) is the existence of the LINGO language, which can easily extend the function of SW3D contents.

The conversion of LightwWave 3D objects into the SW3D format requires them to be exported in a w3d format and then imported into a Macromedia Director, which is a major authoring tool for ShockWave contents. Using Director, we incorporated some special features such as object movement, rotation, or contact judgment in a LINGO manner.

\subsection{Operation}

We show an example screen shot of our contents in Figure 3. This picture explains the method of memory module insertion into the motherboard. The instruction is written in Japanese at the lower left. The learner can move the virtual memory module by dragging the mouse. The viewpoint can also be changed by dragging while pressing the shift- key. After successful module insertion into the proper memory slot, the learners can proceed to the next lesson.

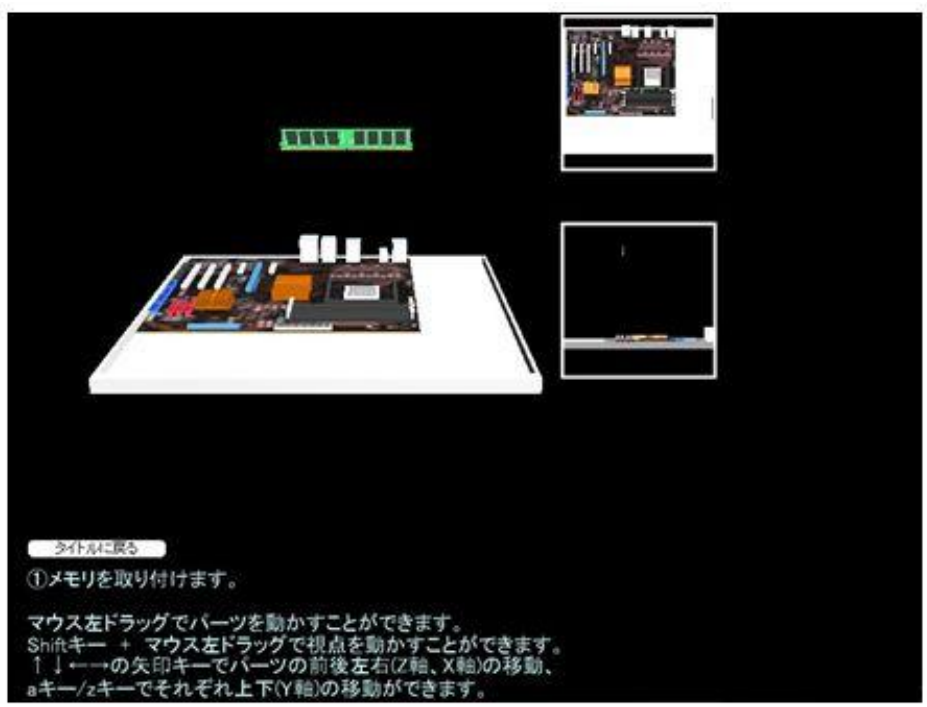

Figure 3. Screen shot of Memory Module Insertion

Unfortunately, we could not include all processes of PC assembly into our contents at that time. Moreover, although our system works quite well, it is difficult to move the virtual PC parts to the correct position in a virtual 3D world using a 2D display 
which cannot realize a proper perspective. Therefore we decided to adapt our system to 3D stereoscopic environments.

\section{Stereoscopic Environments}

Stereoscopy has a relatively long history. Its origin dates back to the late 19th century. In fact, its philosophy is quite simple and it provides just two images, one for the right eye and the other for the left eye. These images are combined in the observer's mind, and the binocular parallax between the two images results in a recognition of perspective. Many other methods such as "anaglyph" and "lenticular prints" have been developed throughout the history for realizing stereoscopy.

In the case of a 3D stereoscopic computer display, there are two major methods: 1) liquid crystal display shutter (LCDS) and 2) circularly polarization (CP). Both of these methods the viewer is required to wear 3D glasses. LCDS glasses must be connected to the computer in a certain way for synchronization. The display shows right and left pictures alternately in a very rapid sequence ( $\sim 8$ frames per s.). The shutter on the rightside of LCDS glasses flips up (i.e., turns off the LCD) when the picture for the right eye appears in the display, while the left-side shutter flips down, and vice versa. The advantage of this type of the system is that it is available even with an ordinary monitor whose vertical-sync frequency is sufficiently large.

nVIDIA 3D VISION (nVIDIA Corporation, 2009) is a typical example of this type of system. It consists of a USB IR transmitter (Figure 4a) and 3D glasses (Figure 4b) that have a built-in IR receiver and a rechargeable battery. This is the best approach to realize nVIDIA stereoscopy, which can be supported by an nVIDIA video chip that is newer than GeForce 8. It also requires a version of Microsoft Windows that is later than Vista and an LCD whose vertical-sync frequency is higher than $120 \mathrm{~Hz}$ (or CRT whose vertical-sync frequency is higher than $100 \mathrm{~Hz}$ ). The IR signals facilitate the synchronization between the monitor and the lenses of the glasses. Using this system, almost all 3D games that are based on Direct3D can be made stereoscopic without the need to be any customize. The display resolution independence is also a remarkable feature of this system. However, the glasses used by this system are relatively heavy and "flicker" is an essential problem that is unique to such systems.

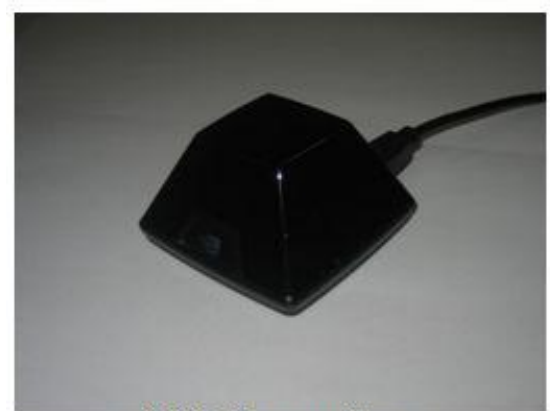

a) IR Transmitter

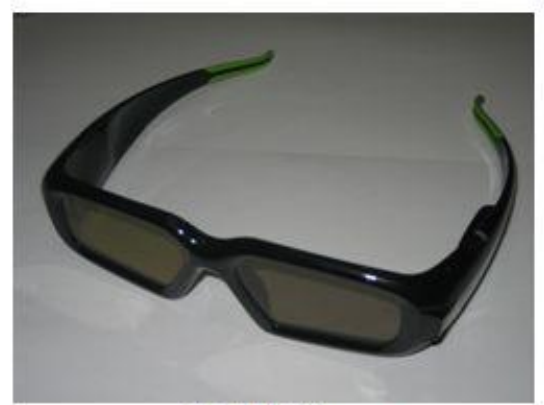

b) 3D Glasses

Figure 4. nVIDIA 3D VISION System

The glasses for CP systems consist of two circular-polarizing filters, which have different polarizations. For example, let us consider the case where the filter on the right has right-handed polarization and that on the left has left-handed polarization. The display shows pictures simultaneously on both sides, but their polarizations are different. 
Hence, the right eye of the observer looks only at the picture on the right and the left eye looks only at the picture on the left. The $\mathrm{CP}$ method does not require a physical connection to the glasses. Therefore, the glasses are relatively light and this type of system has become common in 3D movie theaters.

Unlike the above types of displays, which require special glasses, stereoscopy can be realized using a parallax-barrier-based 3D display without the need for glasses. Both the right and left images are sliced into vertical strips and the left and right strips are then alternately positioned on the screen. The slit (parallax barrier) in front of the screen prevents the right image from arriving at the left eye, and vice versa.

\section{System Implementation}

Initially, it was necessary to discard SW3D, which was the basis of the preliminary contents (Sec. 2) because of its incompatibility with nVIDIA stereoscopy. We reused the LightWave modeling data of all PC parts by converting them into the DirectX file format. Using Microsoft Visual C\# Express 2008 with Microsoft XNA Game Studio 3.1, the contents were then rebuilt. This software tool provides a game development environment for Xbox, Zune, and Windows. These are freely available for download on the MSDN website (Microsoft Corporation, 2009). Regardless of the fact that the most recent release of these software packages occurred in December 2010, (version 2010 and 4.0, respectively), the decision was taken to use a prior release since there is some difficulty in developing nVIDIA stereoscopy-compatible applications in the recent environments.

We have identified 13 steps that are necessary for PC assembly and the contents that were developed have stages that correspond to those steps. The stages are as follows:

Stage 1: Insert the memory module into the proper slot of the motherboard

Stage 2: Insert the CPU into the proper socket of the motherboard

Stage 3: Place the CPU cooler on the CPU

Stage 3-1: Select the proper terminal of the motherboard to connect the CPU fan cable

Stage 4: Insert the videocard into the proper slot of the motherboard

Stage 5-1: Insert HDD into the proper bay of the case

Stage 5-2: Select the proper terminal of HDD to connect the SATA cable from the motherboard

Stage 6-1: Insert the DVD drive into the proper bay of the case

Stage 6-2: Select the SATA terminal of the DVD drive to connect the SATA cable from the motherboard

Stage 7-1: Insert the power unit into the proper place of the case

Stage 7-2: Select the proper terminal of the motherboard to connect the power cable from the power unit

Stage 7-3: Select the proper terminal of HDD to connect the power cable from the power unit

Stage 7-4: Select the proper terminal of the DVD drive to connect the power cable from the power unit 
In addition, Stage 0 , which contains a completed model for all the above stages, is provided for practice. It is observed that there are two types of activities: insertion and selection. In "insertion," the learner can move the parts (such as memory module or CPU) by pressing arrow keys (right/left/forward/backward) and [A]/[Z] keys (up/down). When the learner has placed the parts into their correct positions, the stage is deemed to have been successfully completed. If the parts are inserted into wrong positions, the number of retries increases by 1 and the parts and the camera are returned to their initial positions. "Selection" requires the left mouse button to be clicked on the correct place in order for the stage to be deemed as completed.

For both activities, learners can rotate the camera by dragging the right mouse button in order to change their perspective. When this mission has been accomplished, the learners can proceed to the next stage. The number of retries, the number of the right mouse button pressing, the time taken for the completion of the stage and total time during the right mouse button dragging are automatically counted. This information is presented upon completion of each stage. For example, we show a screen(figure 5) shot of stage 1 of our 3D stereoscopic contents. This is a mixture of the right and left images. Such a mixed image will become stereoscopic to viewers using special glasses and viewing the images on a $3 \mathrm{D}$ display screen.

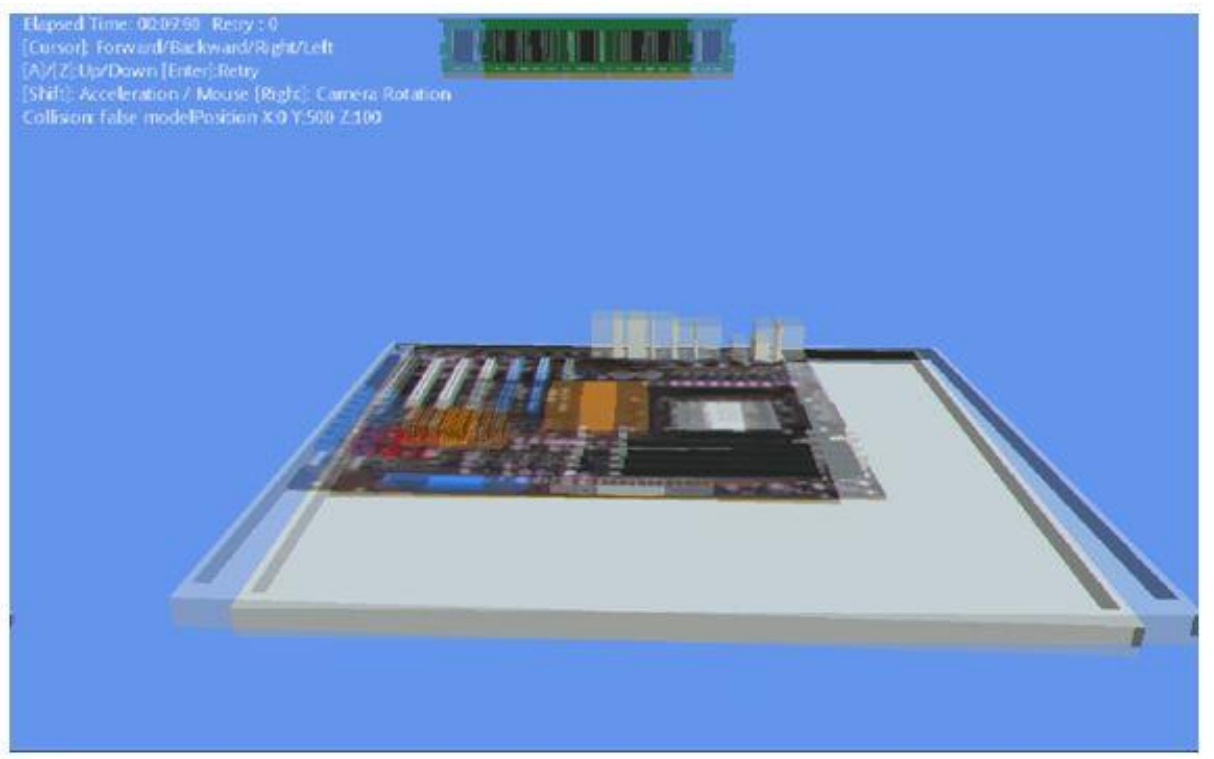

Figure 5. 3D Version of Our Contents

\section{Evaluation Methodology}

In this section, we present our strategy for evaluating the learning effects of our contents in the case of stereoscopic environments. We partially referred to Yamamoto's study (2010) in order to construct the methodology. 


\subsection{Null Hypothesis}

Our aim is to prove the hypothesis: "stereoscopic 3D contents are more suited than the traditional contents for the enhancement of learning." Herein, we state a null hypothesis corresponding to the above: "There is no great distinction between the learning effects of stereoscopic 3D contents and traditional contents." This hypothesis can be proven incorrect if desirable results are obtained.

\subsection{Methods of Analysis}

In this study, we target students who belong to the Department of Media-Informatics of our institute because our contents are designed for use in the course "Major Lab/Exercise II.” The numbers of samples are 28 for 2D contents and 25 for 3D contents.

After learning has taken place, a written examination is conducted. The learners are separated into two groups. One uses stereoscopic environment (nVIDIA 3D VISION with CRT) and the other uses conventional 2D environment (the display is the same as 3D group but 3D VISION is disabled). To clarify the educational effect of stereoscopy, learning will be performed using same contents for both groups.

After the examination has been completed, the result is summarized and then analyzed statistically using independent samples t-test to prove our hypothesis. Similarly, we test the differences in the elapsed time, the average time during the right mouse button pressing (total time of the right mouse button pressing divided by number of the right mouse button pressing) and the number of retries between the 2D and 3D groups. If 3D stereoscopic contents are more effective than $2 \mathrm{D}$ ones, the elapsed time, the average time during the right mouse button dragging and the number of retries in $3 \mathrm{D}$ cases are expected to be reduced relative to $2 \mathrm{D}$ cases. We also have a questionnaire for the learners about the contents.

\section{Results}

Tables 1-7 and Figures 6-8 show the experimental and questionnaire results, respectively. In the case of the elapsed time and the number of retries, there were no obvious differences between the $2 \mathrm{D}$ and $3 \mathrm{D}$ groups except for stage 2 . However, for many stages, the 2D group's results were slightly superior to those of the 3D group. In the case of the average time during the right mouse dragging, obvious differences are shown in seven stages. However, all these significant results indicate the superiority of the $2 \mathrm{D}$ group. We also examined the correlation between the elapsed time or the number of retries and the examination score. However, no significant results were observed.

Table 1. Elapsed Time in Stage1 - Stage5-2

\begin{tabular}{|c|c|c|c|r|r|r|r|r|}
\hline Stage & Contents & stage1 & stage2 & stage3-1 & stage3-2 & stage4 & stage5-1 & stage5-2 \\
\hline \multirow{2}{*}{ Average } & 2D & 55.96091 & 42.12364 & 117.7845 & 120.8532 & 107.4327 & 61.87273 & 42.83318 \\
\cline { 2 - 9 } & 3D & 74.29652 & 134.1322 & 179.55 & 183.1848 & 172.0326 & 87.12 & 85.51087 \\
\hline \multirow{2}{*}{ Distribution } & 2D & 1200.022 & 1369.595 & 14355.46 & 15956.72 & 12411.98 & 4019.733 & 2039.086 \\
\cline { 2 - 9 } & 3D & 2592.372 & 33484.54 & 26889.41 & 42509.27 & 52501.42 & 17125.7 & 24354.1 \\
\hline \multicolumn{2}{|c|}{ Significance(P=0.05) } & $\mathrm{N}$ & $\mathrm{Y}$ & $\mathrm{N}$ & $\mathrm{N}$ & $\mathrm{N}$ & $\mathrm{N}$ & $\mathrm{N}$ \\
\hline
\end{tabular}


Table 2. Elapsed Time in Stage6-1 - Stage7-4 and Total

\begin{tabular}{|c|c|c|c|c|c|c|c|c|}
\hline Stage & Contents & stage6-1 & stage6-2 & stage7-1 & stage7-2 & stage7-3 & stage7-4 & $\begin{array}{c}\text { stage- } \\
\text { total }\end{array}$ \\
\hline \multirow{2}{*}{ Average } & 2D & 26.25 & 17.16455 & 77.78727 & 38.95545 & 72.99636 & 12.80455 & 794.8191 \\
\cline { 2 - 10 } & 3D & 38.61739 & 15.71783 & 116.2313 & 42.17174 & 62.84783 & 12.49913 & 1203.912 \\
\hline \multirow{2}{*}{ Distribution } & 2D & 214.568 & 973.6346 & 7823.042 & 3380.407 & 10816.32 & 363.1889 & 169721.3 \\
\cline { 2 - 9 } & 3D & 1416.688 & 1425.817 & 18751.96 & 4024.039 & 9086.912 & 143.0714 & 763514.3 \\
\hline \multicolumn{2}{|r}{ Significance (P=0.05) } & $\mathrm{N}$ & $\mathrm{N}$ & $\mathrm{N}$ & $\mathrm{N}$ & $\mathrm{N}$ & $\mathrm{N}$ & $\mathrm{N}$ \\
\hline
\end{tabular}

Table 3. Number of Retries in Stage1 - Stage5-2

\begin{tabular}{|c|c|c|c|c|c|c|c|c|}
\hline Stage & Contents & stage1 & stage2 & stage3-1 & stage3-2 & stage4 & stage5-1 & stage5-2 \\
\hline \multirow{2}{*}{ Average } & $2 \mathrm{D}$ & 1.045455 & 0.909091 & 4.681818 & 11.63636 & 3.090909 & 1.363636 & 4.136364 \\
\hline & $3 D$ & 1.347826 & 3.782609 & 5.565217 & 12.13043 & 4.26087 & 1.565217 & 6.73913 \\
\hline \multirow{2}{*}{ Distribution } & $2 \mathrm{D}$ & 2.140693 & 2.943723 & 30.41775 & 266.9091 & 31.03896 & 2.813853 & 28.98052 \\
\hline & 3D & 3.509881 & 38.17787 & 25.52964 & 203.8458 & 39.29249 & 22.71146 & 112.8379 \\
\hline \multicolumn{2}{|c|}{ Significance $(P=0.05)$} & $\mathrm{N}$ & $Y$ & $\mathrm{~N}$ & $\mathrm{~N}$ & $\mathrm{~N}$ & $\mathrm{~N}$ & $\mathrm{~N}$ \\
\hline
\end{tabular}

Table 4. Number of Retries in Stage6-1 - Stage7-4 and Total

\begin{tabular}{|c|c|c|c|c|r|r|r|c|}
\hline Stage & Contents & stage6-1 & stage6-2 & stage7-1 & stage7-2 & stage7-3 & stage7-4 & $\begin{array}{c}\text { stage- } \\
\text { total }\end{array}$ \\
\hline \multirow{2}{*}{ Average } & 2D & 0.772727 & 1.636364 & 1.181818 & 5.5 & 7.5 & 0.636364 & 44.09091 \\
\cline { 2 - 9 } & 3D & 0.652174 & 0.826087 & 2.130435 & 2.478261 & 3.956522 & 0.347826 & 45.78261 \\
\hline \multirow{2}{*}{ Distribution } & 2D & 0.755411 & 21.57576 & 3.679654 & 189.6905 & 222.6429 & 2.242424 & 1813.61 \\
\cline { 2 - 9 } & 3D & 1.328063 & 11.05929 & 22.02767 & 13.71542 & 32.67984 & 0.418972 & 1502.905 \\
\hline \multicolumn{2}{|c|}{ Significance(P=0.05) } & $\mathrm{N}$ & $\mathrm{N}$ & $\mathrm{N}$ & $\mathrm{N}$ & $\mathrm{N}$ & $\mathrm{N}$ & $\mathrm{N}$ \\
\hline
\end{tabular}

Table 5. Average Time during the Right Button Dragging in Stage1 - Stage5-2

\begin{tabular}{|c|c|c|c|c|c|c|c|c|}
\hline Stage & Contents & stage1 & stage2 & stage3-1 & stage3-2 & stage4 & stage5-1 & stage $5-2$ \\
\hline \multirow{2}{*}{ Average } & $2 \mathrm{D}$ & 2.76417 & 1.937829 & 2.575321 & 3.045685 & 2.980908 & 3.535222 & 2.101529 \\
\hline & $3 D$ & 4.886552 & 4.319325 & 3.650974 & 3.914587 & 4.548188 & 4.289078 & 3.204794 \\
\hline \multirow{2}{*}{ Distribution } & $2 \mathrm{D}$ & 1.026751 & 0.743469 & 1.047147 & 1.997882 & 1.920394 & 14.07071 & 0.481609 \\
\hline & $3 D$ & 13.50066 & 4.168611 & 2.254129 & 3.414667 & 3.758591 & 7.199067 & 2.62492 \\
\hline \multicolumn{2}{|c|}{ Significance $(P=0.05)$} & $Y$ & $Y$ & $Y$ & $\mathrm{~N}$ & $\bar{Y}$ & $\mathrm{~N}$ & $Y$ \\
\hline
\end{tabular}

Table 6. Average Time during the Right Button Dragging in Stage6-1 - Stage7-4 and Total

\begin{tabular}{|c|c|c|c|c|c|c|c|c|}
\hline Stage & Contents & stage6-1 & stage6-2 & stage7-1 & stage7-2 & stage7-3 & stage7-4 & $\begin{array}{c}\text { stage- } \\
\text { total }\end{array}$ \\
\hline \multirow{2}{*}{ Average } & 2D & 1.746364 & 1.879895 & 3.212203 & 2.11888 & 2.798375 & 2.686326 & 2.640579 \\
\cline { 2 - 9 } & 3D & 3.679515 & 3.182684 & 3.616366 & 2.819601 & 3.562442 & 3.5803 & 3.873126 \\
\hline \multirow{2}{*}{ Distribution } & 2D & 2.450328 & 1.903613 & 16.39233 & 0.682346 & 1.050965 & 2.611548 & 0.264234 \\
\cline { 2 - 9 } & 3D & 9.420519 & 8.794879 & 2.49982 & 3.017705 & 3.425076 & 6.447453 & 1.590538 \\
\hline \multicolumn{2}{|c|}{ Significance(P=0.05) } & $\mathrm{Y}$ & $\mathrm{N}$ & $\mathrm{N}$ & $\mathrm{N}$ & $\mathrm{N}$ & $\mathrm{N}$ & $\mathrm{Y}$ \\
\hline
\end{tabular}




\section{Table 7. Examination Score (Max 13 Points)}

\begin{tabular}{|c|c|c|c|}
\hline \multirow{2}{*}{ Average } & $2 \mathrm{D}$ & 12.04545 & 12.04545 \\
\hline & $3 \mathrm{D}$ & 12.04348 & 12.04348 \\
\hline \multirow{2}{*}{ Distribution } & $2 \mathrm{D}$ & 2.997835 & 2.997835 \\
\hline & $3 \mathrm{D}$ & 3.952569 & 3.952569 \\
\hline \multicolumn{2}{|c|}{ Significance $(P=0.05)$} & $\mathrm{N}$ & $\mathrm{N}$ \\
\hline
\end{tabular}

We investigated the possible reasons for this result, and it was observed that in $3 \mathrm{D}$ cases, the learners often complained of fatigue. This can be seen in the graph of the result of questionnaire Q5 in Figure 7. The vertical-sync frequency of the CRT that we used was $85 \mathrm{~Hz}$. This value is slightly lower than the required frequency of $3 \mathrm{D}$ VISION $(100 \mathrm{~Hz})$. Such inadequacy causes flicker on the screen. It is thought that this might result in fatigue and have a subsequent impact on the result. Moreover, general stereoscopic images involve problems that are referred to as the "puppet-theater effect" and the "cardboard effect" (Yamanoue, Okui, \& Okano, 2006). The puppet-theater effect is an imaginary miniaturization by the observers of stereoscopic images. The observers indicate that the sizes of the objects in the stereoscopic images are smaller than the real ones. In other words, a person in the image resembles a puppet. The cardboard effect refers to the phenomenon in which the observers of stereoscopic images often get the impression that the objects in the images are flattened like a cardboard (i.e., not 3D), although they appear in the correct perspective. These effects are caused by inaccurate configuration of some geometrical parameters such as lens focal length or binocular disparity. Although these were not considered, these effects also contributed to the learners' fatigue.

Q1. Do you think the contents are readable?

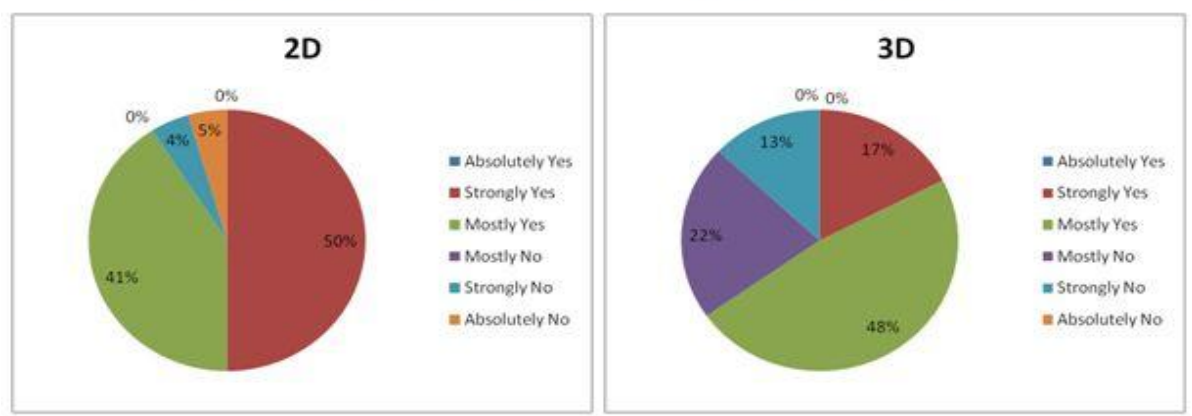

Q2. Do you think the contents are easy to operate?

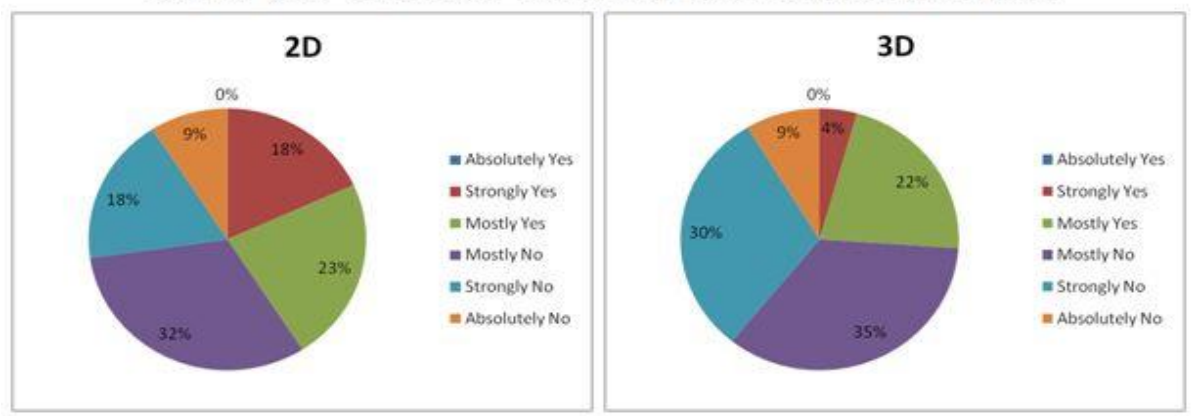

Figure 6. Results of Questionnaire (1) 
Q3. Do you think the contents are easy to understand?

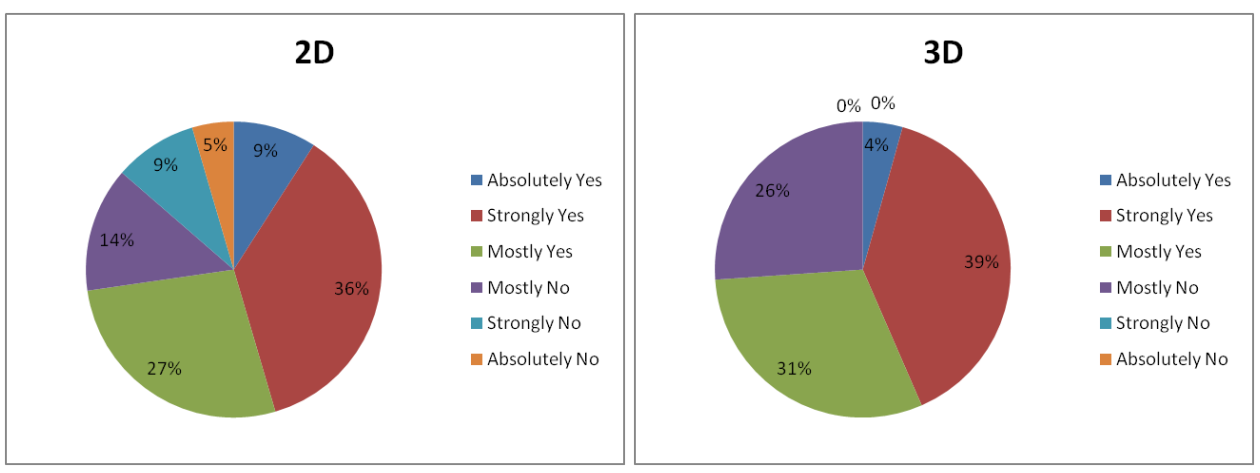

Q4. Did the contents arouse your interests in PC assembly?

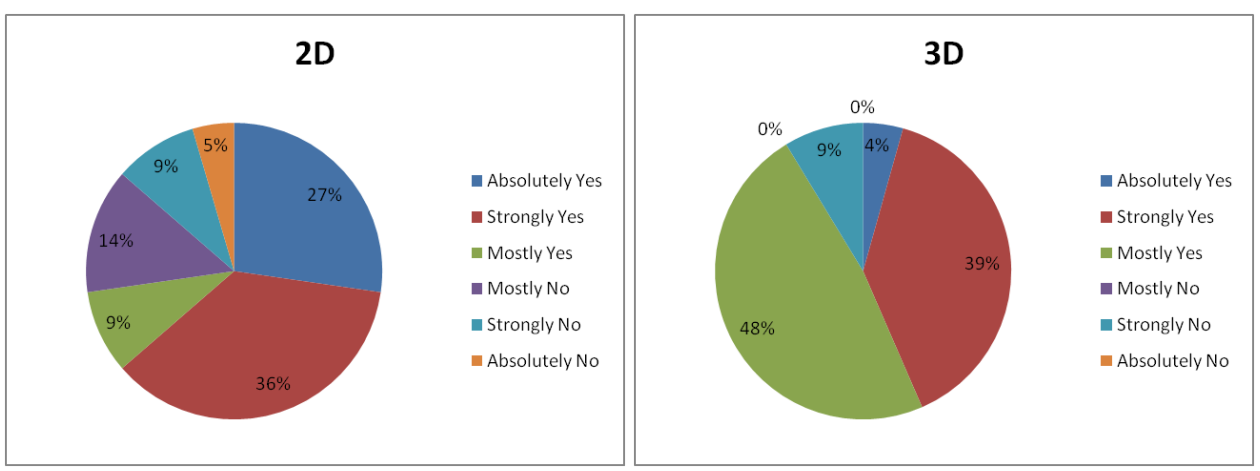

Q5. Have you felt fatigue in your eyes during the experiment?

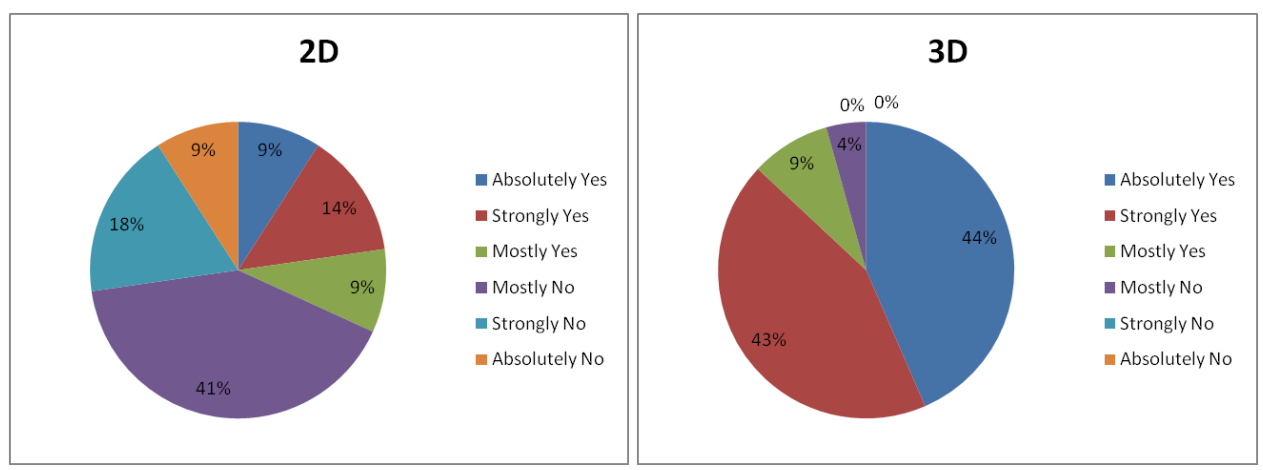

Figure 7. Results of Questionnaire (2) 
Q6. Do you think the contents are useful to learn PC assembly?

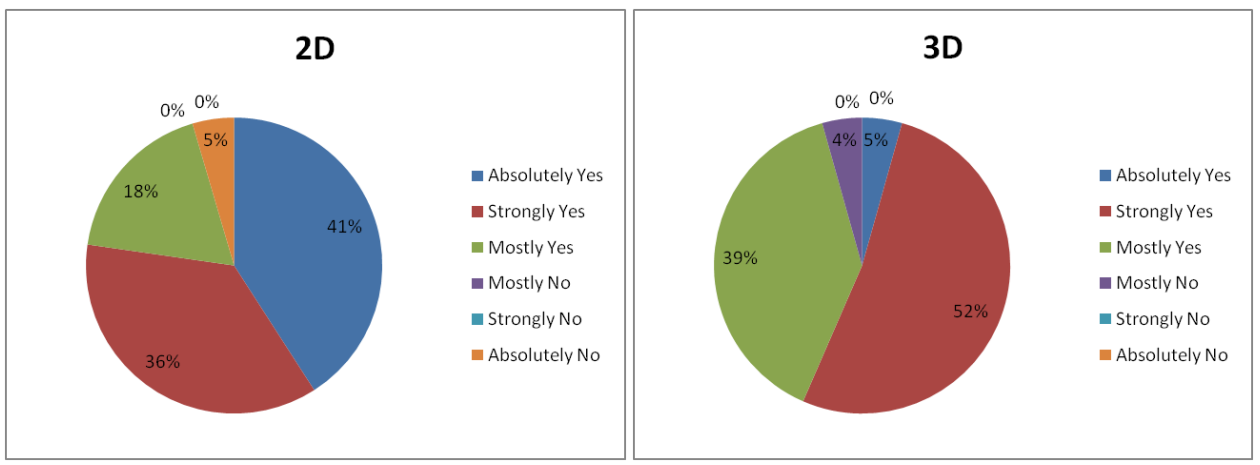

Q7. Did the contents make you feel immersive?

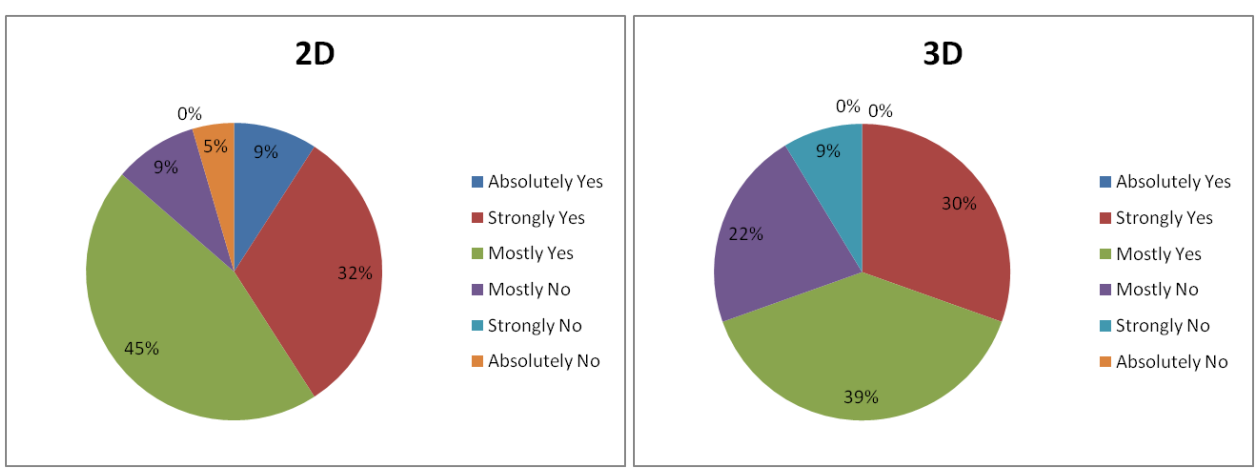

Q8. Do you remember the proper positions of each PC part?

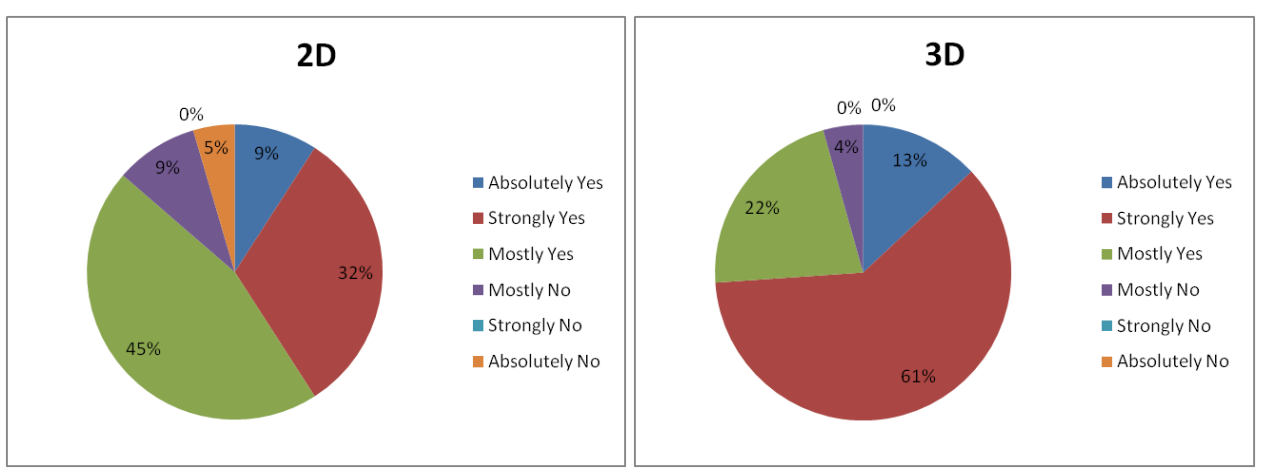

Figure 8. Results of Questionnaire (3) 
Possible another reason for this result is proficiency. The graph of the result of questionnaire Q7 in Figure 8 shows that 2D learners feel more immersive than 3D's. This seems to be contradictory because 3D contents are generally considered to be more realistic than 2D's. However, it must be pointed out that learners have accustomed to conventional 2D display for a long time. In the learner's mind, the discomfort caused by unfamiliar 3D environment might exceed the advantage of realism. Therefore the immersion of 3D learners is probably suppressed. However, this situation might be improved if $3 \mathrm{D}$ environment becomes more common in the near future.

The results of questionnaire Q1and Q2 indicate the inferiority of 3D case. Probably this is also caused by learner's fatigue. Nevertheless, it is remarkable that the percentage of the total negative answers ("Absolutely No" + "Strongly No" + "Mostly No") of Q4 and Q8 are reduced in 3D case. Restricting to the case of learning PC assembly, the 3D stereoscopy might be effective to raise learner's motivation and selfefficacy.

\section{Conclusion and Further Remarks}

In this paper, we discussed the possibility of enhancing the learning experience by introducing 3D stereoscopic environments for handmade PC construction. However, successful results could not be obtained, and hence, the null hypothesis was not denied. However, the trial was not considered to be a failure. As mentioned above, our system involves several problems concerning the learners' fatigue.

Currently, plans are in place for the re-evaluation of our hypothesis using the 3D VISION-ready displays. In addition, the geometrical parameters are adjusted in order to prevent the puppet-theater and cardboard effects. Favorable results are expected since similar trials in anatomical learning have resulted in successful outcomes (Luursema et al., 2008).

In order to enable our contents to become more realistic, the introduction of a special human interface such as a data globe might be effective. In fact, a virtual training system for mechanical manufacturing and maintenance based on Web3D with data globes has been developed and has worked well (Corvaglia, 2004). However, such devices are usually quite expensive and therefore may not be practical.

\section{References}

1. Cerbo, F., Dodero, G., \& Papeleo, L. (2010). Integrating a Web3D Interface into an E-learning Platform. Proceedings of the 15th International Conference on Web 3D Technology (2010) Volume: 1, Issue: 212, Publisher: ACM, pp. 83-92.

2. Corvaglia, D. (2004). Virtual Training for Manufacturing and Maintenance based on Web3D Technologies. In: Proc. of the 1st International Workshop on Web3D Technologies in Learning, Education and Training (LET-WEB3D 2004), Udine, Italy, (2004) 28-33, Retrieved May 31, 2010, from http://hcilab.uniud.it/publications/2004-14/VirtualTraining_LET-WEB3D04.pdf.

3. Cycore System AB. (1997). Cult3D Home [On-line]. Retrieved May 31, 2010, from http://www.cult3d.com/.

4. Hirayama, M.J. (2010). Networked Interactive Education of Foreign Language Conversations: Role-playing in Virtual Communication Environments, 
Proceedings of Asia-Pacific Conference on Technology Enhanced Learning 2010 (APTEL2010), Osaka, Japan, No.120 pp.1-5.

5. Holman, D., Pavlica, K., \& Thorpe, R. (1997). Rethinking Kolb's theory of experimental learning in management education, The contribution of social constructionism and activity theory. Management Learning, 28(2), 125-148.

6. Kolb, D.A., Rubin, I.M., \& McIntyre, J.M. (1974). Organizational Psychology: A Book of Readings ( 2nd edition). Englewood Cliffs, N.J.: Prentice-Hall.

7. Lee, A., \& Berge, Z. (2011). Second Life in Healthcare Education: Virtual Environment's Potential to Improve Patient Safety. Knowledge Management \& ELearning: An International Journal (KM\&EL), 3(1), 17-23.

8. Linden Lab. (2003). Second Life Official Site [On-line], Retrieved May 31, 2010, from http://secondlife.com/.

9. Luursema, J.M., Verwey, W.B., Kommers, P.A.M., \& Annema, J.H. (2008). The role of stereopsis in virtual anatomical learning. Interacting with Computers, 20(45), 455-460.

10. Macromedia Inc. (2001). Shockwave Player version history[On-line]. Retrieved May 31, 2010, from http://kb2.adobe.com/cps/148/tn_14820.html.

11. Mayer, R. E. (2001). Multimedia learning. New York: Cambridge University Press. ISBN 0-52178-749-1.

12. Microsoft Corporation. (2009). Microsoft XNA Game Studio 3.1[On-line]. $\begin{array}{llll}\text { Retrieved May 31, 2010, from } & \end{array}$ http://www.microsoft.com/downloads/en/details.aspx?FamilyID=80782277-d58442d2-8024-893fcd9d3e82.

13. Mohler, J. (2000). Re-examining 3D Web Technologies for Education. In Proceedings of WebNet World Conference on the WWW and Internet 2000 (pp. 402-407). Chesapeake, VA: AACE.

14. Moreno, R., \& Mayer, R. (1999). Cognitive principles of multimedia learning: The role of modality and contiguity. Journal of Educational Psychology, 91, 358-368.

15. NewTek Inc. (1994). NewTek LightWave [On-line] Retrieved May 31, 2010, from http://www.newtek.com/lightwave/.

16. nVIDIA Corporation. (2009). NVIDIA 3D Vision[On-line]. Retrieved May 31, 2010, from http://www.nvidia.com/object/3d-vision-main.html.

17. Pang, L., Jiang, G., Zhou, Y., \& Yu, M. (2006). Research and Application of Stereoscopic Video Based e-Learning System. Technologies for E-Learning and Digital Entertainment (pp.156-160) Vol. 3942/2006, Springer Berlin/Heidelberg, $\begin{array}{llll}\text { Retrieved } \quad \text { May 2010, from } & \text { 31, }\end{array}$ http://www.springerlink.com/content/120p116r73765x77/.

18. Piazza, J. (2010). Audiences experience 'Avatar' blues. [On-line] Retrieved May 31, 2010 , from http://edition.cnn.com/2010/SHOWBIZ/Movies/01/11/avatar.movie.blues/index.ht $\underline{\mathrm{ml}}$.

19. Viewpoint Corporation. (2000). Viewpoint - An Internet Marketing Technology Company[On-line]. Retrieved May 31, 2010, from http://www.viewpoint.com/.

20. Web3D Consortium. (1999). Web3D Consortium | Open Standards for Real-Time $3 D$ Communication [On-line] . Retrieved May 31, 2010, from http://www.web3d.org/realtime-3d/.

21. Yamagishi, Y., \& Tsuruoka, T. (2009). Graduation Thesis, Kanazawa Inst. Tech. 
22. Yamamoto, T. (2010). A Proposal for Measuring Interactivity that Brings Learning Effectiveness. Knowledge Management \& E-Learning: An International Journal (KM\&EL), 2(1), 6-16.

23. Yamanoue, H., Okui, M., \& Okano, F. (2006). Geometrical analysis of puppettheater and cardboard effects in stereoscopic HDTV images., IEEE Transactions on Circuits and Systems for Video Technology, 16(6), 744-752. 